Arch Virol (1987) 96:29-38

\title{
Antigenic and biological diversity of feline coronaviruses: feline infectious peritonitis and feline enteritis virus*
}

\author{
G. T. Tupper1, J. F. Evermann ${ }^{3}$, R. G. Russell ${ }^{2}$, and M. E. Thouless ${ }^{1,2}$ \\ I Department of Pathobiology, and \\ 2 Division of Animal Medicine, University of Washington, Seattle, and \\ ${ }^{3}$ Department of Veterinary Clinical Medicine and Surgery, \\ College of Veterinary Medicine, Washington State University, \\ Pullman, Washington, U.S.A.
}

Accepted March 21, 1987

\begin{abstract}
Summary
Antigenically related feline coronaviruses cause two distinct disease manifestations in infected cats. The diseases are feline infectious peritonitis (FIP), in which the virus is widely disseminated, and feline enteric coronavirus (FECV), a mild disease in which the virus is usually limited to the villi. These two viruses were found to differ in their growth in cell culture. FIPV grows to higher titer, forms larger plaques and switches off host cell protein synthesis more effectively than FECV. Cross neutralization studies showed antigenic differences between the strains. There also appeared to be a difference in the nucleoprotein molecular weight of the viruses causing these two different disease syndromes.
\end{abstract}

\section{Introduction}

Antigenically related feline coronaviruses (FCV) cause two different disease manifestations in cats $(12,14,15,17)$. The first is known as feline infectious peritonitis (FIP), and is characterized by peritonitis and/or pleuritis with occasional central nervous system and ocular involvement (7). The inflammatory infiltrate consists of lymphocytes, plasma cells, and macrophages resulting in either nonsuppurative or a granulomatous inflammation. The second disease is caused by feline enteric coronavirus (FECV) and is a subclinical or mild enteric infection in which lesions are located in the upper third of the villi of the small intestine (16). Although these viruses are associated with very different disease syndromes, evidence has

\footnotetext{
* This work was supported by grant NIH/RR 01203-07.
} 
suggested that the viruses are antigenically and biologically similar (12). It was reported that both virus strains produce relatively large plaques in cell culture and grew to fairly high titers (1). In addition, their polypeptides appeared to be the same molecular weight by immunoblotting (1). Although the strains causing peritonitis and enteritis in cats were antigenically and biologically similar; neither protected against infection with the other (17). Therefore, we investigated the antigenic biological and biochemical properties of these viruses in more detail.

\section{Materials and methods}

\section{Cells}

The viruses were grown in Crandell Feline Kidney (CrFK) cells. The cells were mycoplasma free by the method of Kenny (9). Cells were grown at $37^{\circ} \mathrm{O}$ in Eagle's minimum. essential medium (Auto-Pow, Flow Lab., McClean, VA) supplemented with 10 percent heat inactivated fetal calf serum, $2 \mathrm{~mm}$ L-Glutamine, $12 \mathrm{~mm}$ sodium bicarbonate, $10 \mathrm{~mm}$ HEPES, $10 \mu \mathrm{g} / \mathrm{ml}$ streptomycin, and $100 \mathrm{Units} / \mathrm{ml}$ of penicillin (MEM-10). The calf serum was reduced to 1 percent for virus propagation (MEM-1).

\section{Viruses}

The FIP strains WSU 79-1146 and NOR 15, and the FECV strains WSU 79-1683 isolates of FCV were studied. The viruses were cloned by endpoint titration 3 times in microtiter plates. The isolation and in vivo pathogenicity of these strains has been previously reported $(3,12,17)$.

\section{Virus titration and plaque size measurement}

Virus titers were measured by a plaque assay or a $\mathrm{TCID}_{50}$ endpoint. The plaque assay was done in $60 \mathrm{~mm}$ tissue culture petri dishes (Corning, NY). Confluent monolayers of CrFK cells were inoculated with $200 \mu \mathrm{l}$ of a tenfold virus dilution. After adsorption for 1 hour at $37^{\circ} \mathrm{C}$ an overlay media of $4 \mathrm{ml}$ of warmed 0.7 percent carboxymethyl cellulose in MEM-1 was added. Monolayers were fixed with formalin and stained with 1 percent crystal violet five days post infection (PI). Plaques were counted using a light box and a plaque counting device (Scientifica). The TCDD 50 assay for virus infectivity was done in 96 well microtiter plates (FALCON) by infection of 6 wells with $25 \mu \mathrm{l}$ of a tenfold virus dilution. The monolayers were fixed and stained after 5 days. Wells were examined for cytopathic effects (CPE) and the formula of Reed and Muench was used to calculate the TCID 50 (18). Photographs of infected monolayers in $60 \mathrm{~mm}$ plates containing approximately 80 distinct plaques were enlarged 11.5 times to determine the average plaque size. The diameters of the plaques were measured with a ruler.

\section{Virus purification}

$\mathrm{CrFK}$ cells were grown in roller bottles at $37^{\circ} \mathrm{C}$ and infected with the feline coronavirus strains at a multiplicity of infection (MOI) of 1.0 to 0.1 . The supernatant was harvested and pooled at 46 hours PI. All subsequent steps were carried out at $4^{\circ} \mathrm{C}$ similar to the procedure used by Schmidt and Kenny (22). The suspension was elarified by centrifugation at $4000 \times \mathrm{g}$ for 30 minutes. Polyethylene glycol 8000 was added to make a final concentration of 7 percent $(\mathrm{w} / \mathrm{v})$. After a 12 hour incubation the precipitate was collected by clarification at $13,200 \times \mathrm{g}$ for 40 minutes. The pellets were resuspended in HEPES Buffer (20.0 mu HEPES-0.15 M NaCl-5.0 mm EDTA-Na 2, pH 7.0) layered onto a 15 and 55 
percent $(\mathrm{w} / \mathrm{v})$ sucrose step gradient, and centrifuged at $120,000 \times \mathrm{g}$ for 2.5 hours in a Beckman SW 28 rotor. The virus bands at the interface were collected, diluted with an equal volume of HEPES buffer and pelleted by centrifugation at $243,000 \times \mathrm{g}$ for 20 minutes in a Beckman SW 50.1. The virus was resuspended in the HEPES buffer for inoculation into rabbits to obtain hyperimmune sera.

Further purification by isopycnic banding was undertaken to obtain purified virus for PAGE. The virus bands were concentrated on a $1 \mathrm{ml}$ cushion of $1.20 \mathrm{gm} / \mathrm{ml}$ renografin (Squibb) in a SW 50.1 rotor. The concentrated virus was again diluted in the HEPES buffer and layered onto a continuous 1.10 to $1.25(\mathrm{gm} / \mathrm{ml}$ ) renografin gradient for isopyenic banding using a Beckman type 65 rotor at $176,000 \times \mathrm{g}$ for 18 hours. The visible bands were collected (density $1.18 \mathrm{gm} / \mathrm{ml}$ ) and then pelleted using a Beckman SW 50.1 rotor. Virus pellets were resuspended in HEPES buffer and frozen until further use. Viral infectivity was measured by $\mathrm{TCID}_{50}$ and the protein concentrations were determined by the Lowry method (11)

\section{Preparation of antisera}

Rabbits were hyperimmunized with FIPV $79-1146$ or FECV $79-1683$ purified by sucrose rate zonal centrifugation as described above. The rabbit immunization schedule was an intramuscular injection of $1 \times 10^{8}$ plaque forming units (PFU)/ml in Freund's incomplete adjuvant, followed by four small intravenous boosts using doses of 0.1 to $0.4 \mathrm{ml}$ of inocula containing $1 \times 10^{8} \mathrm{PFU} / \mathrm{ml}(8)$. The rabbits were bled 10 days after the last boost.

\section{Neutralization}

Virus neutralization was carried out in 96 well microtiter plates (20). Virus, $\left(100\right.$ TCID $_{50}$ virus in $25 \mu \mathrm{l}$ ), was added to $26 \mu \mathrm{l}$ of serial twofold dilutions of rabbit hyperimmune sera against FIPV 79-1146 or FECV 79-1683. The virus-serum mixture was incubated at room temperature for 1 hour after which $1.5 \times 10^{5}$ CrFK cells in $50 \mu \mathrm{l} \mathrm{MEM-1}$ was added. Plates were placed in a 2.5 percent $\mathrm{CO}_{2}$ incubator at $37^{\circ} \mathrm{C}$ for 24 to 48 hours. Monolayers were fixed with formalin, stained with 1 percent crystal violet stain.

\section{Polyacrylamide gel electrophoresis (PAGE)}

PAGE was performed in $1.5 \mathrm{~mm}$ thick slab gels by the method of Laemmli (10). Purified virus samples $(30 \mu \mathrm{g})$ in buffer $(0.1 \mathrm{M}$ Tris- $\mathrm{HCl}, \mathrm{pH} 7.0,2$ percent mercaptoethanol, 2 percent sodium dodecyl sulfate [SDS] and 10 percent glycerol plus bromophenol blue) were boiled for 2 minutes and placed into each well. Proteins were migrated through a stacking gel containing 3.5 percent polyacrylamide and resolved using a 5 to 18 percent continuous polyacrylamide gradient gel. A modified silver stain was used to stain protein (13). The molecular weight of virus structural proteins was determined by using molecular weight standards (Sigma, St. Louis, MO).

\section{Radiolabelling}

The procedure was similar to that used to label rotavirus polypeptides (26). Monolayers were prepared in 6 well (Costar, Cambridge, MA) tissue culture plates by adding $2 \times 10^{6}$ cells $/$ well. The monolayers were washed once and infected with a MOI of 5 . Virus was allowed to adsorb for 1 hour and then $5 \mu \mathrm{g}$ actinomyein D (Sigma) in $1 \mathrm{ml}$ MEM-1 was added. The infected cells were incubated for the desired time, washed three times and $1 \mathrm{ml}$ of $10 \mu \mathrm{Ci} / \mathrm{ml}{ }^{35} \mathrm{~S}-$ methionine in methionine free MEM-1 was added. The plates were incubated for 1 hour at $37^{\circ} \mathrm{C}$ at which time the media was removed and the monolayers washed once. Disruption mixture $(50 \mathrm{~mm}$ Tris- $\mathrm{HCl}, \mathrm{pH} 7.0,5$ percent mercaptoethanol, 2 percent SDS, and 3 percent glycerol with bromophenol blue) in a $0.5 \mathrm{ml}$ volume at $80^{\circ} \mathrm{C}$ was added. Samples were treated with an ultrasonic probe and kept at $-70^{\circ} \mathrm{C}$ until used. 
Cell controls of uninfected cells were treated in the same manner. An amount of sample containing 7000 to 10,000 counts was used per lane for PAGE. Some of the gels were stained with 0.5 percent Coomassie blue in 45 percent isopropanol 10 percent acetic acid and destained in 45 percent isopropanol 10 percent acetic acid. Dried gels were exposed to Kodak film for autoradiography.

\section{Results}

\section{Plaque size and titer}

Virus titers were reproducible throughout the study with FIPV strains 79-1146 and NOR 15 having virus titers of $\sim 1 \times 10^{7} \mathrm{PFU} / \mathrm{ml}$ and FECV 79 1683 having a lower titer of $\sim 3 \times 10^{6} \mathrm{PFU} / \mathrm{ml}$. The cytopathic effect produced by the three feline coronavirus isolates was characterized by syncytial formation. The plaques of the 79-1146 and NOR 15 strains measured $1.12 \mathrm{~mm}$ with a $\pm 0.23 \mathrm{~mm}$ standard deviation while the $79-1683$ strain produced smaller plaques of $0.58 \mathrm{~mm}$ with a $\pm 0.23 \mathrm{~mm}$ standard deviation (Fig. 1) in 5 days in CrFK. The plaque size of the FECV 79-1683 strain were significantly smaller than those of the other two FIPV strains by the T test $(\mathrm{P}=0.01)$.

\section{Virus neutralization}

The 79-1146 and the NOR 15 FIP isolates were distinct from the 79-1683 FECV isolate by virus neutralization using homologous and heterologous antisera prepared in rabbits against 79-1146 and 79-1683 (Table 1). The neutralizing titers for FIPV 79-1146 and NOR 15 were similar irrespective of the antiserum used. By comparison, the FECV 79-1683 strain had a 32 fold difference in neutralization titer using antisera against 79-1146 and a 8 fold difference when antisera against 79-1683 was used. These results suggest that 79-1146 and NOR 15 strains are antigenically similar by virus neutralization and are distinct from the 79-1683 strain of feline coronavirus.

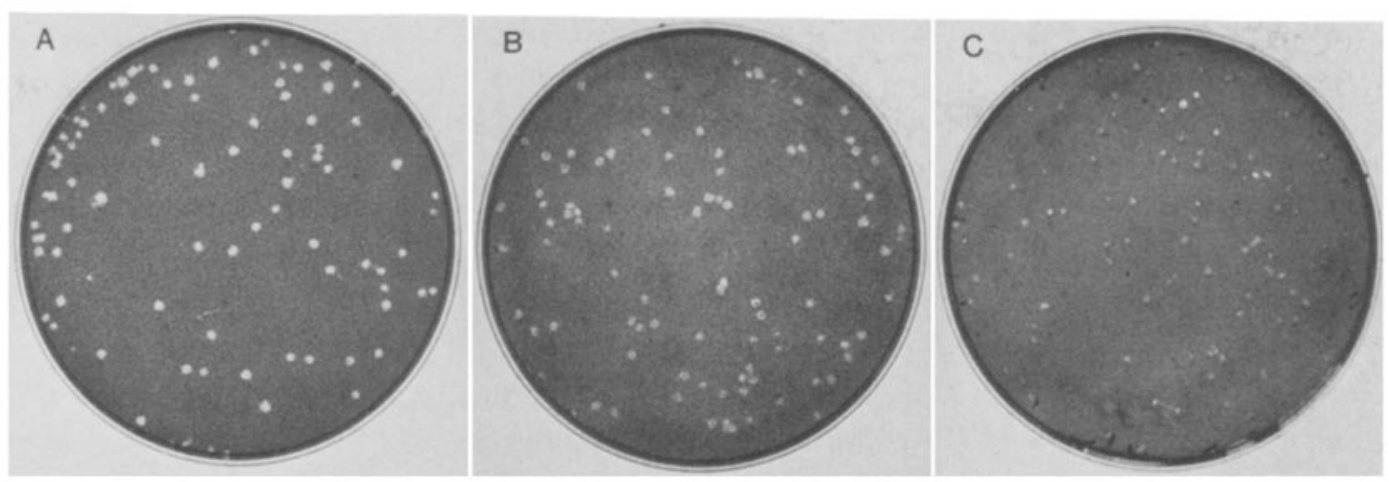

Fig. 1. Plaque sizes of feline coronavirus strains in CrFK cells five days post infection:

A $79-1146$, B NOR 15, C 79-1683 


\section{Polyacrylamide gel electrophoresis}

Each of the three virus strains had the structural protein profile characteristic of that reported for the coronavirus family (24). The peplomer $(\mathrm{P})$ surface protein band measured 205,000 molecular weight (MW). The mem-

Table 1. Neutralization of three feline coronavirus strains by hyperimmune serum against the 79-1149 and $79-1683$ isolates

\begin{tabular}{lll}
\hline & \multicolumn{2}{c}{ Antiserum } \\
\cline { 2 - 3 } Virus isolate & $79-1146$ & $79-1683$ \\
\hline FIP $79-1146$ & $1: 640^{\circ}$ & $1: 20$ \\
FIP NOR 15 & $1: 640$ & $1: 20$ \\
FECV $79-1683$ & $1: 20$ & $1: 160$ \\
\hline
\end{tabular}

a Neutralization antibody titers are the reciprocal of the serum dilution giving 100 percent inhibition of virus $\mathrm{CPE}$

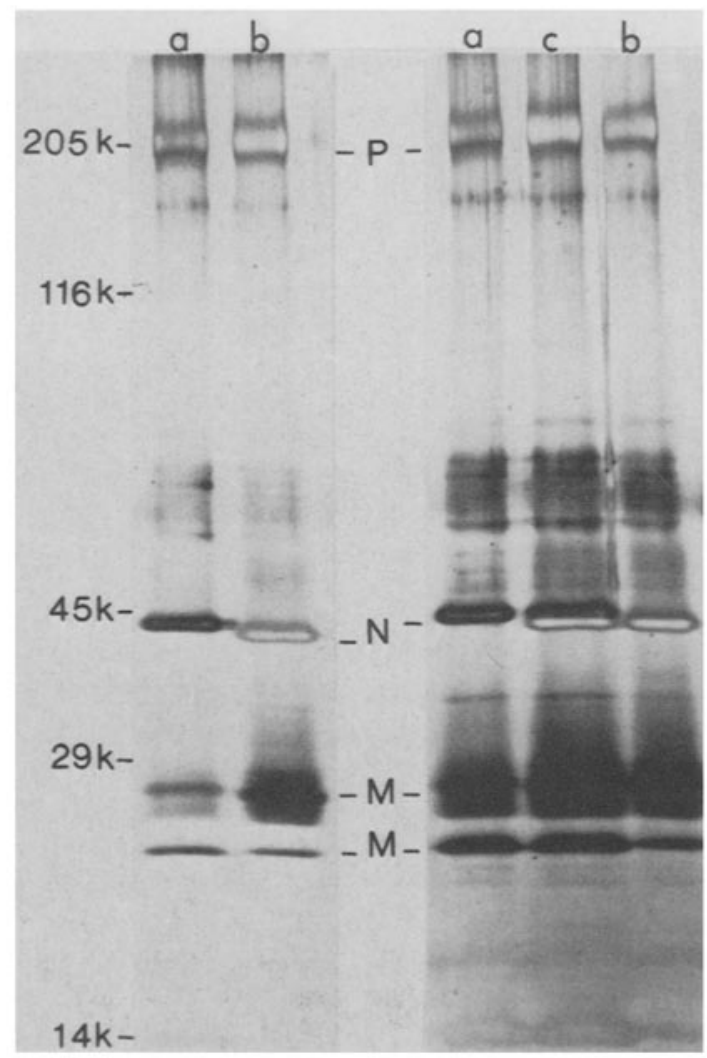

Fig. 2. Comparison of purified virus in PAGE with a silver stain: a 79-1146 FIP, b 79-1683 FECV, c mixture. Numbers on left represent MW markers 
brane protein (M) produced a wide band at 23,000 to 27,000 MW. These were identical for the three strains tested. The nucleoprotein bands of FIPV 79-1146 and NOR 15 had a molecular weight of 42,000. The molecular weight of the FECV 79-1683 nucleoprotein (N) was consistently distinct from the other two strains and estimated to be $43,000 \mathrm{MW}$. The difference was observed with both purified virus and radiolabelled virus in PAGE (Figs. 2 and 3 ). This indicated the differences were consistent and were not due to maturation artifact. There was a cell protein band just above the nucleoprotein of the FECV 79-1683 of the radiolabelled virus. This band was not present in the purified virus preparation or in radiolabelled 79-1146 where host cell synthesis was switched off.

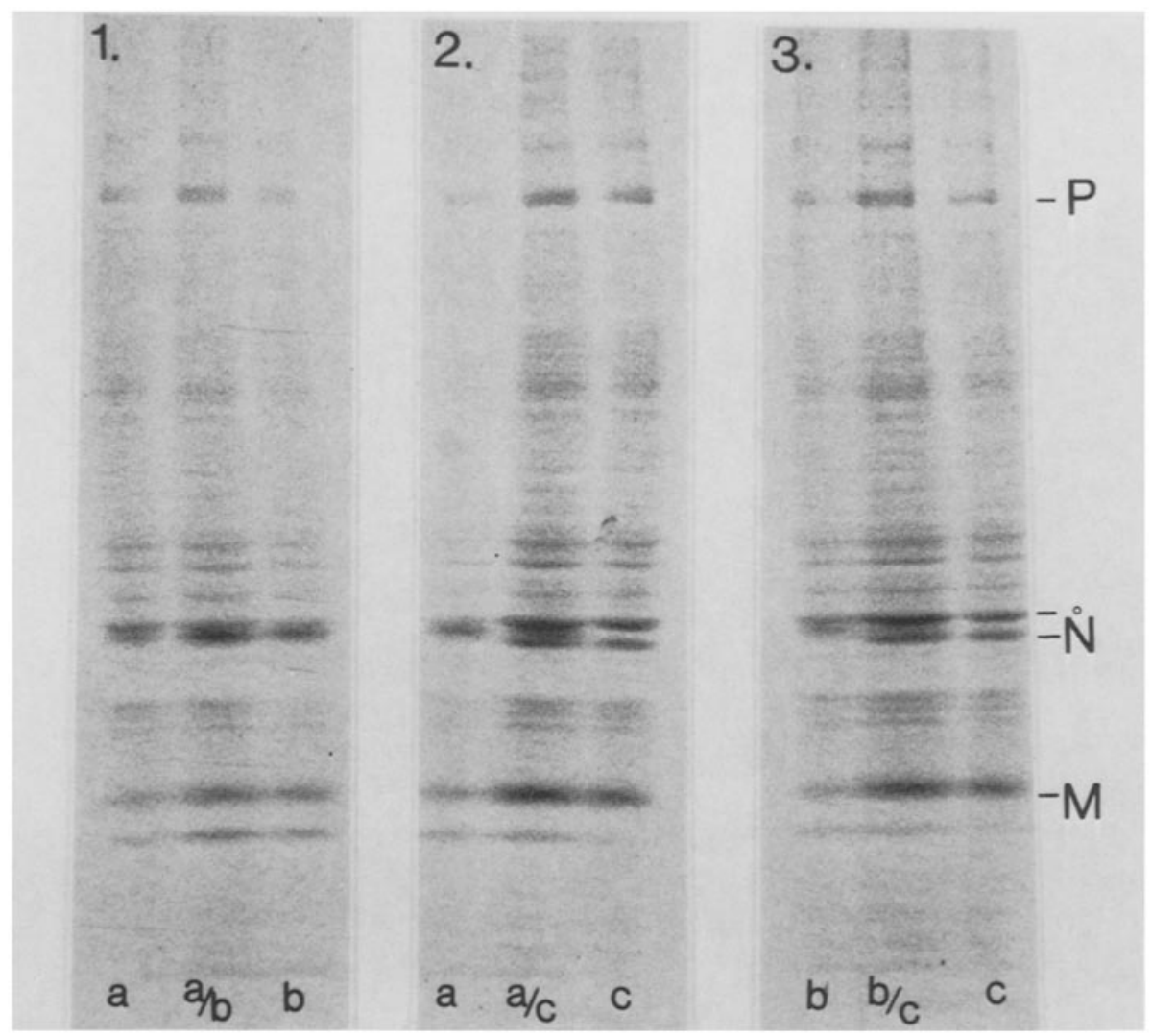

Fig. 3. Comparison of virus structural proteins 12 hours post infection. Each frame contains two viruses and a mixture of the two viruses in the middle lane. Virus isolate: a 79 . 1146 FIP, b NOR 15 FIP, and $c$ 79-1683 FECV. The comparisons: $179-1146$ and NOR 15, 2 79-1146 and 79-1683, and 3 NOR 15 and 79-1683. Virus structural proteins: $P$ surface protein, peplomer; $N$ nucleoprotein; $M$ membrane. The small open circle denotes the cell protein present only in the 79-1683 samples 
Inhibition of cellular protein synthesis

Virus proteins appeared at 6 hours PI and continued to be synthesized throughout the 14 hour study period. In the presence of actinomycin $\mathrm{D}$, FIPV 79-1146 shutoff protein synthesis of CrFK cells at 8 to 10 hours post infection, NOR 15 at 10 to 12 hours. Cellular protein synthesis was reduced at 8 hours PI by FECV 79-1683 but was not completely shutoff (Fig. 4). The feline coronavirus strains did not shutoff cellular protein synthesis in the absence of actinomycin D.

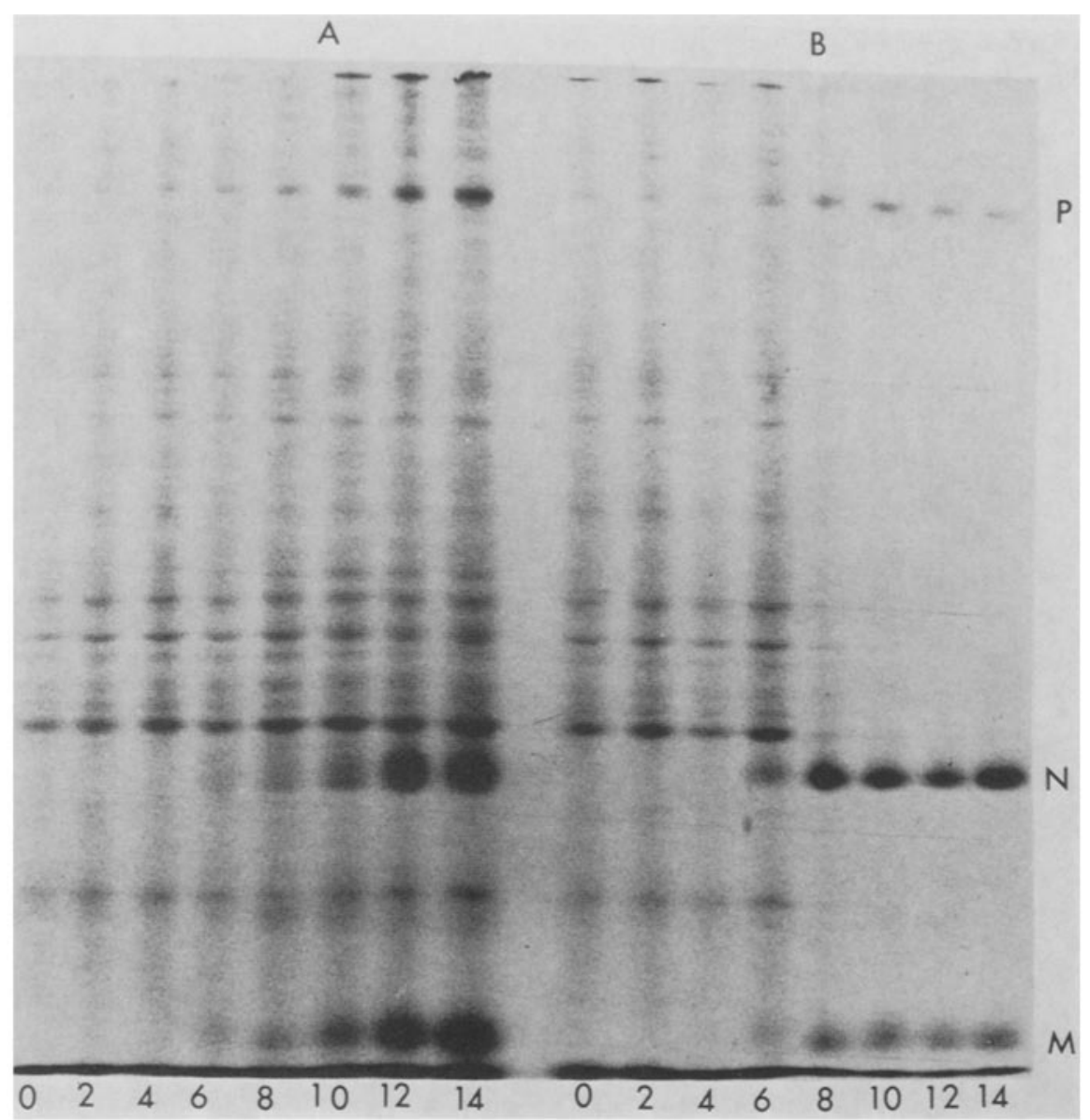

Fig. 4. Time study of the formation of feline coronavirus proteins in CrFK cells: $\mathbf{A}$ FECV 79-1183, B FTP 79-1146. Virus proteins: $P$ surface protein, peplomer; $N$ nucleoprotein; $M$ membrane protein. $0-14$ The number of hours post infection the culture was pulse labelled with ${ }^{35} \mathrm{~S}-$ methionine 


\section{Discussion}

The 79-1146, NOR 15, and 79-1683 isolates of feline coronavirus have previously been reported to be similar by their relatively high titer in cell culture, large plaque size, and by indirect immunofluorescence with antibody to canine coronavirus (3). This study showed similarities between the 79-1146 and the NOR 15 isolates of FIPV and difference with the 79-1683 FECV isolate.

The FIPV strains produced larger plaques in CrFK cells and half a log higher titer of virus than the FECV strain. Use of a different cell line (fcwL-4 cells) and time that the plaques were left to develop may have accounted for the fact that Boyle et al. (1) did not find a difference. However, differences in plaque size and virus titers have been reported for human, murine and porcine coronaviruses grown in different cell lines $(1,2,4,5)$.

The FIPV strains could be distinguished from the FECV strain by cross neutralization. The low level of cross reactivity with heterologous serum compared to homologous serum suggests considerable antigenic variation between the two groups. However the sera were not very high titer despite immunization of rabbits with biologically cloned purified virus, perhaps due to the fragility of the peplomer protein which induces neutralizing antibody (6). No differences were seen in the molecular weights of the peplomer but this might be undetectable in such a high molecular weight protein where the relevant epitope may be only a very small part of the entity. Previous studies with convalescent sera from naturally and experimentally infected cats did not show these differences in vitro $(16,17)$ but did in vivo where FIPV strains did not protect against FECV infection and prior FECV infection even seemed to enhance the pathogenicity of FIPV.

The molecular weight of the nucleoproteins differed by about 1000, with the FECV strain nucleoprotein being smaller than that of the 2 FIPV strains. This was determined by co-running purified virus and pulse radiolabelled polypeptides of both strains. This is considered to be a more sensitive technique than immunoblotting used by Boyle et al. (1), and may explain the fact that they did not observe this difference. The significance of the difference in the molecular weight and any possible relationship to pathogenicity is unknown at the present time. However, differences in molecular weight of the nucleoproteins have been found in 5 strains of murine coronaviruses and a high degree of homology was found between them by hybridization kinetics and peptide mapping (2).

In vitro infection with the FIPV strains reduced the production of host cell proteins. This effect was enhanced by actinomycin D. The FECV strain did not switch off host cell synthesis even in the presence of actinomycin D. Host cell protein synthesis was also shut off by infection with murine coronavirus and different strains vary in the extent to which they do it (25). Highly 
lytic strains of MCV synthesize all 3 structural polypeptides synchronously whereas the nucleoprotein appears earlier than the other two polypeptides in less lytic infections $(19,23)$. In this study, all 3 structural polypeptides appeared synchronously in cells infected with FIPV or FECV strains. It is interesting that the more vigorously growing strains which produce more varied and severe disease (FIPV) shut off host cell synthesis more effectively than the less pathogenic FECV strain. Despite the aforementioned differences, there is currently no evidence that the in vitro differences between the virus strains studied are associated with or linked to the differences in the pathogenicity of FIPV and FECV strains in vivo.

\section{Acknowledgements}

The authors wish to express their appreciation to A. J. MeKeirnan for assistance with feline coronavirus strains.

\section{References}

1. Boyle JF, Pedersen NC, Evermann JF, McKeirnan AJ, Ott RL, Black JW (1984) Plaque assay, polypeptide composition, and immunochemistry of feline infectious peritonitis virus and feline enteric coronavirus isolates. Adv Exp Med Biol 173: 133-147

2. Cheley S, Morris VL, Cupples MJ, Anderson R (1981) RNA and polypeptide homology among murine coronavirus. Virology 115: 310-321

3. Evermann JF, Baumgartener L, Ott RL, Davis EV, McKeirnan AJ (1981) Characterization of a feline infectious peritonitis virus isolate. Vet Pathol 18, 256-265

4. Flintoff WF (1984) Replication of murine coronaviruses in somatic cell hybrids formed between a mouse fibroblast cell line and either a rat schwannoma line or a rat glioma line. Adv Exp Med Biol 173: 301-313

5. Garwes DJ, Bountiff L, Millson GC, Elleman CJ (1984) Defective replication of poreine transmissible gastroenteritis virus in a continuous cell line. Adv Exp Med Biol 173: $79-93$

6. Garwes DJ, Pocock DH, Pike BV (1976) Isolation of subviral components from transmissible gastroenteritis virus. J Gen Virol 32: 283-294

7. Horzinek MC, Osterhaus ADME (1979) The virology and pathogenesis of feline infectious peritonitis. Arch Virol 59: 1-15

8. Kenny GE (1971) Immunogenicity of mycoplasma pneumoniae. Infect Immun 3: 510515

9. Kenny GE (1973) Contamination of mammalian cells in culture with myeoplasmata. In: Fogh $J(e d)$ Contamination in tissue culture. Academic Press, New York, pp 107129

10. Laemmli UK (1970) Cleavage of structural proteins during the assembly of the head of bacteriophage T 4. Nature 227: $680-685$

11. Lowry OH, Rosebrough NJ, Farr AL, Randall RJ (1951) Protein measurement with the folin phenol reagent. J Biol Chem 193: 265-275

12. McKeirnan AJ, Evermann JF, Hargis A, Miller LM, Ott RL (1981) Isolation of feline coronavirus from two cats with diverse disease manifestations. Feline Pract 11: 16-20

13. Oakley BR, Kirsch DR, Morris NR (1980) A simplified ultrasensitive silver strain for detecting proteins in polyacrylamide gels. Anal Biochem 105: 361-363 
14. Pedersen NC (1983) Feline infectious peritonitis and feline enteric coronavirus infection II. Feline infectious peritonitis. Feline Pract 13: 5-20

15. Pedersen NC, Black JW, Boyle JF, Evermann JF, McKeirnan AJ, Ott RL (1984) Pathogenic differences between various feline coronavirus isolates. Adv Exp Med Biol 173: $365-380$

16. Pedersen NC, Boyle JF, Floyd K (1981) An enteric coronavirus infection and its relationship to feline infectious peritonitis. Am $J$ Vet Res 42: 368-377

17. Pedersen NC, Evermann JF, MeKeirnan Ad, Ott L (1984) Pathogenicity studies of feline coronavirus isolates 79-1146 and 79-1683. Am J Vet Res 45: 2580-2585

18. Reed LJ, Muench H (1938) A simple method for estimating fifty percent endpoints. Am J Hyg 27: 493-497

19. Rottier PJM, Horzinek MC, van der Zeijst BAM (1981) Viral protein synthesis in mouse hepatitis virus strain A 59-infected cells: effect of tunicamycin. J Virol 40:350357

20. Sever $J(1962)$ Application of a microtechnique to viral serological investigation. $J$ Immunol 88: $320-329$

21. Schmidt OW, Cooney MK, Kenny GE (1979) Plaque assay and improved yield of human coronaviruses in a human rhabdomyosarcoma cell line. J Clin Micr 9: 722-728

22. Schmidt OW, Kenny GE (1981) Immunogenicity and antigenicity of human coronaviruses $229 \mathrm{E}$ and $\mathrm{OC} 43$. Infect Immun 32: 1000-1006

23. Siddell SG, Wege H, Barthel A, ter Meulen V (1981) Coronavirus JHM: intracellular protein synthesis. J Gen Virol 53: 145-155

24. Siddell St, Wege $H$, ter Meulen $V$ (1982) The structure and replication of coronaviruses. Curr Top Microbiol Immunol 99: 131-163

25. Sturman LS, Holmes KV (1983) The molecular biology of coronaviruses. Adv Virus Res 28: 35-112

26. Thouless ME (1979) Rotavirus polypeptides. J Gen Virol 44: 187-197

27. Wege H, Siddell St, ter Meulen V (1982) The biology and pathogenesis of coronaviruses. Curr Top Microbiol Immunol 99: 165-200

Authors' address: Dr. M. E. Thouless, Department of Pathobiology SC-38, University of Washington, Seattle, WA 98195 , U.S.A.

Received August 21, 1986 